\title{
As potencialidades e as limitações das diferentes linguagens no processo de ensino em geografia: uma reflexão pedagógica para o uso do cinema
}

\author{
The potentialities and the limitations of different languages in the process \\ of teaching in geography: a pedagogical reflection for the use of the \\ cinema
}

\author{
Valdemira Pereira Canêjo de Andrade; Francisco Kennedy Silva dos Santos"; Josias \\ Ivanildo Flores de Carvalho"I
}

\section{RESUMO}

O presente artigo se propõe a problematizar e refletir as diferentes linguagens no ensino de Geografia proporcionando aulas mais dinâmicas e criativas na prática docente. Diante desta proposição e apoiando-se em diversos teóricos para entendimento do objeto de estudo que tratam das diferentes linguagens no processo de ensino em Geografia, nos colocamos diante do desafio de compreender as potencialidades e as limitações no uso das diferentes linguagens na prática docente a partir do cinema como linguagem midiática e propositiva e, seus rebatimentos na construção dos conceitos geográficos, bem como, identificar os desafios dos educadores para recriarem suas práticas docentes e inserir filmes nas aulas de Geografia. Mediante as exigências do objeto optou-se pela pesquisa qualitativa, tendo como procedimento o levantamento bibliográfico e a análise documental. Neste intuito, as formas de linguagens no ensino de Geografia possibilita a prática do professor sair de um trabalho criteriosamente planejado, pronto e acabado propiciando os alunos caminhos diferentes para a construção do conhecimento geográfico. Por isso, é necessário explorar as diferentes habilidades e competências intelectuais, atitudes e valores morais de cada aluno e da sociedade como um todo. Portanto, este trabalho contribui para que os educandos sintam-se estimulados a questionar e discutir de forma participativa nas aulas e problematizem o contexto social de sua realização.

Palavras-chave: Potencialidades e Limitações; Formas de linguagens; Ensino de Geografia

\section{ABSTRACT}

This article proposes to problematize and reflect the different languages in the teaching of geography providing more dynamic and creative classes in teaching practice. Given this proposition and relying on various theorists to understand the object of study that deal with different languages in the process of teaching in geography, we face the challenge of understanding the potentialities and limitations in the use of different languages in teaching practice from of the cinema as a media and propositional language, and its rebounds in the construction of geographical concepts, as well as identify the challenges of educators to | Engenheiro Agrônomo, servidor público efetivo da Secretaria Especial de Agricultura Familiar e Desenvolvimento Agrário da Casa Civil. E-mail: rodrisou@hotmail.com
|| Graduada em Geografia pelo Instituto de Estudos Sócio-Ambientais. Atualmente aluna do Programa de Pós-Graduação em Geografia-IESA/UFG. E-mail: iza.chaves.93@gmail.com III Mestranda no Programa de Pós-Graduação em Geografia - PPGEO, Instituto de Estudos Socioambientais - IESA, Universidade Federal de Goiás - UFG. E-mail: geoiesalx@gmail.com IV Mestranda em Geografia na área de Dinâmica Socioespacial na UFG. gabrielalicengeo@gmail.com

$\checkmark$ Tem experiência na área de Geociências, com ênfase em Climatologia Geográfica

joaoneto-94@hotmail.com 
recreate their teaching practices and insert films in geography classes. Due to the requirements of the object, a qualitative research was chosen, having as procedure the bibliographic survey and the documental analysis. In this sense, the forms of languages in the teaching of geography enable the practice of the teacher to leave a carefully planned work, ready and finished providing students with different paths for the construction of geographic knowledge. Therefore, it is necessary to explore the different intellectual skills and competencies, attitudes and moral values of each student and society as a whole. Therefore, this work contributes for the students to feel stimulated to question and discuss in a participatory way in the classes and to question the social context of its accomplishment.

Keywords: Potentialities and limitations; The forms of languages; Teaching of Geography

\section{INTRODUÇÃO}

No cotidiano escolar percebe-se que os professores além de ministrar suas respectivas aulas, cumprem outras atribuições inerentes à profissão, tais como seguir o calendário apresentado pela Secretaria de Educação, correções de avaliações da aprendizagem dentre outras funções. Sair da rotina do dia a dia escolar e trazer outros elementos importantes para a formação dos educandos é difícil para o professor, nesse sentido, é importante ressaltarmos que a carga horária das aulas de Geografia também tem influência na questão. É um desafio para o professor despertar o interesse ou a curiosidade dos alunos, a construção do conhecimento e sua respectiva contextualização com o seu meio, que pode ser seu cotidiano e os acontecimentos da sociedade global. Buscar outras atividades, de forma que venha a contribuir significativamente para o aprimoramento intelectual, crítico e ético dos alunos, é fundamental para a prática do professor na contemporaneidade.

Sendo assim, inserir outras linguagens no processo de ensino-aprendizagem em Geografia é essencial, refletindo desta maneira para uma formação críticoreflexiva dos discentes, na intenção de contribuir significativamente para a construção de habilidades e competências, aprimoramento intelectual, crítico e ético dos alunos, para que os discentes intervenham nas problemáticas sociais, ambientais, políticas e culturais, sendo este um dos papéis do ensino de Geografia na escola (BARBOSA, 2008). Porém, cabe destacar que inserir as diferentes linguagens necessariamente não torna a formação critico-reflexiva, pois o professor pode inserir as diversas linguagens em uma aula, mas não construir um espaço para reflexão, isso vai depender da maneira que será conduzida. 
Complementando as ideias de Barbosa (2008), os autores Oliveira Jr. e Girardi (2011, p. 05) ressaltam que:

Podemos avançar na problematização do tema das diferentes linguagens no ensino da geografia, tratando as linguagens não somente como componentes do ato comunicativo, mas também, e, sobretudo, como viabilizadoras de novas produções de mundo. E seguir nesta problematização implica, necessariamente, em questionar o próprio conteúdo do processo comunicativo. Abordar as diferentes linguagens é entendê-las não estritamente como elemento de um processo de comunicação, mas como fundamento de um processo de criação, de produção de pensamento sobre o espaço.

Neste sentido, a inserção de outras linguagens não é algo recente e tampouco novo, mas tem se destacado pelos professores em seus trabalhos escolares. Através de seu uso em sala de aula, a prática do professor torna-se enriquecedora, motivadora, prazerosa e construtiva, com isso, o livro didático vem sendo um dos suportes ao ensino, pois com a utilização de outras formas de linguagem para o ensino em Geografia, como a literatura, a música, a imagem e o cinema, como apresentado no trabalho, a aula torna-se dinâmica e tende a despertar a atenção dos alunos para o processo de construção de aprendizagem. Os autores Santos e Chiapetti (2011, p. 02) salientam:

Para a construção do conhecimento, é necessária uma relação do sujeito aprendente como seu objeto de conhecimento e, nesse sentido os professores devem ser os mediadores da aprendizagem. Não existem mais espaços para aulas centradas apenas no quadro-negro (ou branco) e no livro didático. Os professores devem lançar mão de outras ferramentas pedagógicas para tornar o ensino mais atraente e prazeroso e relacioná-lo ao dia-a-dia dos alunos. Assim, a utilização de recursos didático pedagógicos alternativos, como as atividades lúdicas, constitui-se numa poderosa ferramenta, que permite trabalhar os conteúdos geográficos de modo crítico e criativo.

Nesta perspectiva, surge as seguintes inquietações iniciais: Quais as potencialidades e as limitações na prática docente no uso das diferentes linguagens, envolvendo cinema, música, literatura, teatro e histórias em quadrinhos dentre outras linguagens? Como planejar e ministrar aulas de Geografia, em duas aulas semanais com duração de 50 minutos cada, e inserir outras formas de linguagens? Como inserir a linguagem cinematográfica nas aulas de Geografia visando a construção dos conteúdos geográficos por meio de filmes e documentários? 
As reflexões, aqui tratadas, são resultados de um estudo de investigação que tem como objetivo compreender as potencialidades e as limitações das diferentes linguagens no processo de ensino em Geografia e identificar os desafios dos educadores para recriarem suas práticas docentes. Portanto, na tessitura da ação metodológica optou-se pela pesquisa qualitativa como trajeto a percorrer, dado que o fenômeno a ser pesquisado abarcará a interpretação dinâmica em que os fatos não podem ser considerados fora de um contexto social e que raramente podem ser quantificados, mas sim, interpretados, como bem explica Minayo (2002, p. 21-22) "Ou seja, ela trabalha com o universo de significados, motivos, aspirações, crenças, valores e atitudes, o que corresponde a um espaço mais profundo das relações, dos processos e fenômenos que não podem ser reduzidos à operacionalização de variáveis". Tendo como procedimentos o levantamento bibliográfico e a análise documental, na tentativa de discutir com os autores a temática em tela.

Diante do que fora exposto, o presente artigo está organizado em três itens. O primeiro apresenta o professor de Geografia enquanto mediador do conhecimento. $\mathrm{O}$ segundo trata da importância das diferentes linguagens no processo de ensinoaprendizagem nas aulas de Geografia, bem como, as potencialidades e as limitações e o terceiro aborda o uso de filmes nas aulas de Geografia. Por fim, tecemos as nossas considerações finais.

\section{O FAZER PEDAGÓGICO DOS PROFESSORES DE GEOGRAFIA: DILEMAS ENTRE A MECANICIDADE E O CONSTRUIR}

No cotidiano das escolas percebe-se que ser professor de Geografia é um desafio, pois ensinar ultrapassa os muros da escola, de transmitir conhecimento. Ou seja, o profissional de Geografia deve agir como mediador entre os conteúdos e os alunos para que os mesmos relacionem, intervenham e contextualizem com o meio. Para Calori e Pereira (2011, p. 14) "O professor de geografia tem como objetivo central fazer com que seus alunos consigam relacionar de melhor forma possível o seu espaço habitual com as relações de transformações que sucedem". 
Nesta perspectiva, ser professor é atuar como mediador, ou seja, o professor deve se colocar como ponte entre o conhecimento e o aluno, visando reflexão, criticidade, questionamento por si, sem recair unicamente em passar informações (BULGRAEN, 2010). Outro aspecto a ser considerado, é o papel do professor de Geografia no processo educativo, assim, exerce uma função importante na formação dos educandos mediando-os para a construção do conhecimento, cabe-lhe criar situações e mecanismos que permita desenvolver competências, habilidades, aspectos visíveis dos fatos existentes, fenômenos e acontecimentos geográficos. De acordo com as Orientações Curriculares para o Ensino Médio:

[...] o professor tem papel importante no cotidiano escolar e é insubstituível no processo de ensino-aprendizagem, pois é o especialista do componente curricular, cabendo-Ihe o estabelecimento de estratégias de aprendizagem que criem condições para que o aluno adquira a capacidade para analisar sua realidade sob o ponto de vista geográfico. (BRASIL, 2006, p. 46).

O professor de Geografia diante da atual sociedade deve proporcionar a construção de saberes que busque romper com as metodologias enraizadas na reprodução de exercícios e na memorização, tendo em vista que, a Geografia enquanto disciplina escolar ocupa um lugar de luta, especialmente diante do currículo escolar que na maioria das vezes engessa o papel do ensino dessa disciplina tão importante para a formação cidadã, para a reflexão, o olhar crítico, de leitura da realidade, do vivido e do percebido, dos nossos sujeitos de ensino. A Geografia é uma ciência com conhecimentos inacabados, é histórica e está em constante transformação. Com isso, é importante tanto para os professores como para os alunos acompanhar as mudanças do mundo atual, tendo em vista que a Geografia não é somente em sala de aula. Complementando, os Parâmetros Curriculares Nacionais para o Ensino Médio (BRASIL) destaca que:

Nunca o espaço do homem foi tão importante para o desenvolvimento da história. Por isso, a Geografia é a ciência do presente, ou seja, é inspirada na realidade contemporânea. O objetivo principal destes conhecimentos é contribuir para o entendimento do mundo atual, da apropriação dos lugares realizada pelos homens, pois é através da organização do espaço que eles dão sentido aos arranjos econômicos e aos valores sociais e culturais construídos historicamente. (BRASIL, 2000, p. 31, grifo do autor). 
O papel do ensino de Geografia na educação básica possibilita refletir criticamente sobre o espaço, contextualizar os conteúdos apreendidas na sala de aula com o cotidiano do aluno, é uma disciplina pautada nos conhecimentos inacabados; podendo ir além do que nossa visão alcança. Contudo, os conhecimentos geográficos são construídos a partir das trocas de ideias entre os professores e os alunos, onde a participação desses sujeitos possibilita a discussão e construção coletiva, tornando-os ativos no processo de ensino e aprendizagem. Cavalcanti (1998, p. 138) enfatiza que:

Não se trata, então, nem de simplesmente o professor transmitir conhecimento para os alunos, nem de apenas mobilizá-los e entender a suas necessidades imediatas. Ou seja, nesse processo nem é passivo o aluno, nem o professor. $O$ aluno é ativo porque ele é o sujeito do processo e, por isso, sua atividade mental e física é fundamental para a relação ativa com os objetos de conhecimento; o professor é ativo porque é ele que, faz a mediação do aluno com aqueles objetos. Portanto, ambos atuam, ou devem atuar, conjuntamente ante os objetos de conhecimento.

Nesta perspectiva, a participação do professor como sujeito desse processo, do conteúdo trabalhado em sala de aula é importante, pois cabe-Ihe organizar, estruturar e refletir sobre suas aulas, possibilitando com que os educandos relacionem, compreendam e contextualizem. A Geografia é uma disciplina onde o conhecimento deve ser visto e refletido também fora da escola. Onde o aluno possa construir um pensamento espacial da realidade, destacando as questões referentes ao espaço vivido e as múltiplas situações geográficas, os problemas de seu bairro, as questões de sua cidade, levando-os a criticidade e ao surgimento de questionamentos. Para Calori e Pereira (2011, p. 15):

O professor de geografia, ao elaborar determinado conteúdo a ser trabalhado em classe, precisa estruturar suas aulas e prepará-las criando métodos de aprendizagem fazendo com que o aluno perceba e transponha o conhecimento adquirido para o seu cotidiano.

Desse modo, o contexto social em que o professor atua em algumas escolas públicas, enfrenta algumas limitações como a falta de estrutura, material didático, que muitas vezes desestimulam os professores, mas é possível reverter esta situação, cabe aos docentes usarem de sua criatividade diante dos problemas enfrentados no 'chão da escola' e inserir em seu plano de aula atividades pedagógicas, de modo a 
contemplar o ambiente escolar que está inserido. É preciso enfrentar os obstáculos e as reais dificuldades presentes no ambiente escolar para tornar-se um profissional criativo na/sob prática. Para os autores Bereze; Costa; Andrade (2015, p. 79) descrevem que:

Entende-se que quando o docente encontra desafios, como a falta de estruturas e de material didático nas escolas, sua motivação em ensinar deve superar tais obstáculos. Durante a sua formação, ainda na academia, o futuro profissional tem experiências nas realizações dos estágios, mas isso não o prepara suficientemente, apenas mostra uma pequena parcela das dificuldades que irá encontrar. Esta preparação é muito importante, pois quando de fato assume seu papel como professor, deve fazer de sua criatividade um meio a mais que o auxilie nas aulas e atividades pedagógicas diversas.

Diante disso, é através do ensino de Geografia e da leitura espacial que os educandos perceberão que esta disciplina faz parte do processo educativo e da sua vida. Com isso, o professor enquanto mediador do conteúdo-aluno deve ter em mente que os sujeitos são seres curiosos, inacabados e que estão em constante transformação em busca de mais conhecimento. É nesta relação que a aprendizagem se constitui, partindo do conhecimento prévio que os alunos possuem para a construção dos conhecimentos científicos. Na linha de pensamento de Dezotti e Ortiz (2010, p. 85) ressaltam que:

O aluno pode vir a considerar as aulas de Geografia como um bom e agradável momento de aprendizagem escolar, mas isso depende, é claro, da atuação consciente do professor, o qual deve levar em conta que o ser humano é curioso, criativo e transformador, que carrega em si a ansiedade de saber mais. O educador deve ter a consciência de que só fará um trabalho adequado a partir do conhecimento da realidade imediata do seu aluno.

Neste sentido, ser professor vai além da prática cotidiana, é ser criativo para que os alunos percebam a finalidade e o objetivo do ensino, além de compreender como os conteúdos apreendidos na sala de aula fazem parte e pode ser contextualizados em sua vida. É criar sentido e espaço para que o aluno possa refletir e se posicionar de forma crítica.

É importante destacar que não vejamos o professor como único sujeito de todas essas tarefas e informações, para que os alunos também façam parte das ações pedagógicas. Desta forma, professores e alunos podem: investigar, experimentar, falar 
e inovar para a construção da aprendizagem, pois é no diálogo construtivo entre professores e alunos que o aprendizado se produz. O objetivo das aulas de Geografia nesta perspectiva é a formação de indivíduos questionadores, reflexivos e leitores da realidade. Para as Orientações Curriculares para o Ensino Médio ressalta que "É oportuno lembrar que a prática docente adquire qualidade quando existe a produção do saber". (BRASIL, 2006, p. 46). Nesta linha de raciocínio Dezotti e Ortiz destacam que:

O aluno precisa sentir que, nesse espaço (a aula de Geografia), ele poderá falar, relatar, questionar. Aquele tempo em que se buscava o conhecimento pronto nos livros já passou. Agora é o momento de refletir sobre os fatos, relacionando-os com a realidade que os cerca. A Geografia atual busca o entendimento da realidade num sentido amplo. (DEZOTTI; ORTIZ, 2010, p. 85).

Diante deste pressuposto, o educador ao organizar seus saberes na condução de seu trabalho deve levar em consideração os conhecimentos prévios que os alunos trazem para a sala de aula, a fim de construir os conhecimentos científicos concebidos socialmente, portanto, precisa-se ter como prerrogativa a vivência dos alunos na construção de conteúdos, ou seja, as ações docentes precisam estar próximas da dimensão do vivido pelos alunos (CAVALCANTI, 1998).

As Orientações Curriculares para o Ensino Médio (BRASIL) aponta que:

Essa mudança requer muitas vezes a organização dos professores em suas escolas e no contexto escolar em que atuam, uma vez que o professor deixa de dar os conceitos prontos para os alunos para, junto com eles, participar de um processo de construção de conceitos e saberes, levando em consideração o conhecimento prévio. Nesse processo, é fundamental a participação do professor no debate teórico-metodológico, o que Ihe possibilita pensar e planejar a sua prática, quer seja individual, quer seja coletiva. (BRASIL, 2006, p. 47).

Finalmente, enfatiza-se que é desafiador para o educador mobilizar e conduzir os alunos enquanto sujeitos do seu processo de formação para a discussão e da leitura espacial das realidades, além de mostrar que aprender Geografia é significativo para a construção do conhecimento, da formação cidadã, ademais para compreensão dos fatos, acontecimentos geográficos fora e dentro do ambiente escolar. 


\section{AS POTENCIALIDADES E AS LIMITAÇÕES DAS DIFERENTES LINGUAGENS NO} PROCESSO DE ENSINO-APRENDIZAGEM

Abordar as diferentes linguagens nas aulas, como exemplo o cinema, a música, a literatura, o teatro e as histórias em quadrinhos, entre outras linguagens são importantes, mas é necessário que se tenha finalidade e objetivos que são pretendidos alcançar. Deste modo, quando explorados, contribuem significativamente na aprendizagem dos alunos, uma vez que torna-os motivados para entender os conteúdos, podendo ser utilizados na Geografia como em outras disciplinas escolares. A utilização das diferentes linguagens possibilita o aprimoramento da prática do professor, uma maneira de recapitular o que foi trabalhado em sala de aula, dessa forma há uma interação entre professor/disciplina/aluno no processo educativo para a formação. Além disso, proporciona aos educandos uma aprendizagem significativa dos conteúdos curriculares, recriação, produção e construção de pensamento sobre o espaço (SANTOS; CHIAPETTI, 2011). Já os autores Oliveira Jr. e Girardi (2011, p. 03) destacam que:

[...] a escolha da linguagem ou das linguagens a serem utilizadas se dá prioritariamente tendo em vista os objetivos de ensinar e motivar os alunos e elas (as linguagens) são tomadas, em regra, em suas estruturas linguísticas mais habituais, uma vez que a linguagem na qual o ensinar/motivar é realizado não é colocada sob o foco de discussão. Ela é tomada como estrutura que gera obras (frases, mapas, maquetes, filmes, fotografias, pinturas, peça...) as quais atuam no gesto docente pretendido/realizado/relatado.

Nos dias atuais, o ensino de Geografia na escola assume outro papel. Formar cidadãos críticos e atuantes na sociedade, leitores espaciais da realidade, problematizando e questionando de forma crítica, do lugar vivido e do percebido em seu bairro, cidade e no mundo, fazendo relação com os conteúdos. Calori e Pereira dizem que:

O ensino de geografia tem como papel resgatar identidade, fomentar criatividade, colaborar na construção de personalidades equilibradas, capazes de atuar em diversos espaços da sociedade com o diferencial da ética e da cidadania planetária analisando, sentindo e compreendendo a especialidade das práticas sociais para poder intervir nelas a partir da prática cotidiana. (CALORI; PEREIRA, 2011, p. 14-15). 
Com isso, ensinar Geografia vai além do muro da escola, bem como, das informações prontas e acabadas, devendo despertar a criatividade, pois somos seres inacabados, ativos e capazes de atuar na sociedade enquanto cidadãos. O ensino de Geografia na educação básica é significativo para formação dos nossos alunos.

Entre as diferentes linguagens podemos exemplificar a literatura, a música, a imagem dentre outros e o cinema como tratado especificamente no trabalho como subsídio às aulas de Geografia. Através das diferentes linguagens nas aulas de Geografia será possível enriquecer a prática docente a fim de proporcionar aulas mais agradáveis e prazerosas. Para Cecília e Alves (2016, p. 33) "Assim, a geografia escolar com o uso de suas diferentes linguagens contribuirá para uma nova aprendizagem geográfica e um novo olhar para a matéria/disciplina do currículo escolar".

Dentre as possibilidades já existentes, destaca-se o uso da imagem a ser utilizada em sala de aula para o estudo da Geografia visando desenvolver a construção do conhecimento. Dessa forma, as imagens trazem consigo mecanismos que propiciam a aprendizagem, alguns questionamentos podem ser levantados como ponto de partida do professor para que os alunos comecem a problematizar as imagens observadas, como por exemplo: comparar as diferentes imagens, uma vez que cada imagem possui uma bagagem histórica, social, cultural e econômica distinta, ano, autor, paisagem dentre outras questões. Com isso, as imagens são carregadas de significados e oportunizam a visualização do vivido e do percebido. Através da percepção visual, o educando construirá e destacará os elementos presentes na imagem. Para Santana e Barbosa (2015, p. 02-03) "O uso da imagem é um estímulo à percepção visual, projetando caminhos para o ensino de Geografia em que é possível aproximar realidade e criação, ficção e o espaço vivido, superando práticas pedagógicas tradicionais".

Segundo Zatta e Aguiar (2016, p. 08) descrevem que:

O trabalho com imagens pode ser muito útil como forma de ensinar como se produz leitura através do olhar. Isto é fundamental para a Geografia, pois a representação geográfica seja pelos mapas, imagens, fotos, vídeos, paisagens, sempre se coloca em jogo o autor e as técnicas; Onde o professor pode utilizar uma variedade de materiais, como imagens de diferentes épocas, fotografias, imagens de satélite, imagens representadas nos livros didáticos, de jornais, revistas, 
slides, entre outros; sendo recursos bastante significativos para a construção e ampliação de conhecimentos geográficos.

Utilizar as imagens, como exemplo para construção do conceito de paisagem é significativo para entendimento dos alunos cabendo-lhes observar, perceber, comparar e interpretar os elementos constitutivos e as mudanças inerentes a imagem. "Logo, as imagens se constituem uma aliada no ensino da Geografia, para estudo do espaço geográfico e, por conseguinte, para a construção do conceito de paisagem". (SANTANA; BARBOSA, 2015, p. 04-05).

Cabe ressaltar que trabalhar com a imagem requer uma seleção criteriosa, pois nem todas as imagens podem inseridas nas atividades pelo o educador, elas devem estar de acordo com os conteúdos e ideias ao serem usadas em sala de aula para que se atinja a finalidade exata ao público exposto. Com isso, é importante perceber que as diferentes linguagens têm um objetivo a ser atingido para que os alunos possam aprender de forma significativa e dinâmica (CALORI; PEREIRA, 2011).

O uso das diversas linguagens no ensino, na construção do conhecimento geográfico, se faz necessária, especialmente quando utilizadas a partir de uma abordagem do cotidiano dos alunos, propiciando uma aula dinâmica, interativa, deixando-os curiosos, questionadores na busca do saber, mobilizando toda a sala de aula. O objetivo é esse, inserir as diferentes linguagens no ensino com finalidade, coerência visando a problematização e aprendizagem. Conforme Cecília e Alves (2016, p. 29) "As diferentes linguagens proporcionam ao educador trabalhar os conteúdos articulados a uma técnica que facilitará a compreensão do aluno, sendo indispensável à formação do professor- educador para o uso desses recursos (linguagens de mapas, imagens e músicas)".

A linguagem literária também faz parte das ações docentes, visando a formação do conhecimento, não é simplesmente inseri-la, mas analisar, criticar e descrever os elementos oriundos da obra, estimulando a criatividade dos alunos, além de contribuir como ferramenta para uma melhor assimilação do que foi trabalhado em sala de aula de forma crítica. Para os autores Teixeira; Tubino; Suzuki (2011, p.10), "A Literatura define-se, aqui, como uma mediação na leitura da produção do espaço e da 
inserção do sujeito em suas dinâmicas, focos tão caros à Geografia". Contudo, é importante ressaltar que as diversas obras literárias abordam a representação da paisagem, sociedade, cultura e religião, contemplando uma dimensão cultural sobre o espaço e o ser social. Conforme os autores Jaques e Kuehn (2013, p. 65-66) salientam que:

Para ensinar Literatura, a língua deve ser subsidiária do processo e não ao contrário. Deve-se utilizá-la como meio para entender as diversas possibilidades de leitura e interpretação. Analisar gramaticalmente uma obra acaba sendo contraproducente e enfadonho, fazendo que a rejeição à matéria aumente. Assim sendo, o sentido da Literatura como expressão humana e como manifestação artística fica em segundo plano pelos métodos convencionais. Desta forma, não se proporciona a descoberta do valor da literatura e do prazer estético. Na escola aprendemos história literária e não literatura. Não aprendemos a apreciar, analisar e criticar uma obra. Ao contrário do que muitos pensam, análise literária não é apenas análise estilística. $\mathrm{Na}$ análise literária buscamos ressaltar aspectos tradicionais da obra e buscar as inovações do autor. Estudamos o estilo individual e o estilo da época, buscando entender o enquadramento do autor no estilo do período.

Muitos alunos se questionam, o porquê estudar os textos literários, se a explicação for sem sentido, de difícil entendimento, considerarão as obras literárias como chatas. Daí a importância de mostrar aos educandos que a linguagem literária é relevante, abordam vários elementos discutíveis e integram a compreensão e interpretação dos fatos. Quanto à escolha do que ler na escola, o professor deve ficar atento sobre a obra que pode ser inserida para leitura, é importante entender como ensiná-la - o intuito do texto literário nas aulas é despertar nos alunos a reflexão e criticidade, e buscar a memorização das características dos autores, estilos e escolas literárias. Os Parâmetros Curriculares Nacionais do Ensino Médio (BRASIL) aponta que:

A literatura é um bom exemplo do simbólico verbalizado. Guimarães Rosa procurou no interior de Minas Gerais a matéria-prima de sua obra: cenários, modo de pensar, sentir, agir e de ver o mundo, de falar sobre o mundo, uma bagagem brasileira que resgata a brasilidade. Indo às raízes, devastando imagens préconcetiuosas, legitimou acordos e condutas sociais, por meio da criação estética. (BRASIL, 2000, p. 20).

O professor de Geografia enquanto mediador do conhecimento através da inserção da linguagem literária mobiliza todos os alunos a formação do saber, será uma atividade dinâmica provocando a criatividade, habilidade e competência dos 
educandos junto ao professor, resgatando as ideias centrais, levantando pontos, questionando, entendendo a importância de ler e interpretar, todavia, uma leitura crítica das obras literárias trabalhadas pelo professor na sala de aula, possibilitando que os educandos sejam leitores assíduos da obra.

Dentre as diversas linguagens que visam trazer melhorias e motivação para a busca do conhecimento dos educandos destaca-se a música. A linguagem musical contribui para o aproveitamento da aula, requer dos alunos junto ao professor aprimoramento e compreensão da letra, de modo algum ouvir por ouvir, mas dar sentidos, significados, resgatando os elementos constitutivos que a compõe, como o autor da música, o conteúdo da letra, ano, para quem é direcionada a música e que conhecimentos podem ser construídos a partir da letra. Para Silva $(2014$, p. 11) "Com certeza este meio de aprendizagem aprimora o esforço educativo resultando na participação e interesse por parte dos alunos. A música de certa forma traz aos alunos situações vivenciadas em seu cotidiano e é também para eles sinônimo de diversão e alegria". É importante deixar claro que a letra de música tenha relação com o conteúdo e a realidade espacial dos alunos. Silva (2014, p. 10) ressalta que:

\footnotetext{
Dessa maneira, a utilização da música na prática pedagógica permitirá fazer uma análise e reflexão dos conteúdos vistos em sala de aula por meio da dinâmica da nossa sociedade, pois a música também é uma das artes que mais influencia na subjetividade, nos desejos e nos comportamentos humanos por ter a capacidade de mexer com as nossas emoções. Nessa perspectiva, se faz necessário a busca por novas formas de aprendizagem, as quais deve fazer parte do cotidiano dos docentes.
}

O trabalho com a música enriquece a prática do professor e possibilita junto aos alunos estudar, discutir, explorando as letras das músicas, fazendo relação com o ensino. Segundo Silva (2014, p. 12) "Ou seja, é preciso estudar a música e explorar as informações nelas contidas. Deve explorar, da mesma forma, músicas de outras culturas, civilização, grupo social, comunidade, pois cada um tem sua própria expressão musical". Percebe-se que utilizar as diferentes linguagens requer aproximação com o contexto dos alunos, para só assim, os alunos compreenderem o intuito e a função da música na sala de aula. 
Deste modo, para uma boa aula de Geografia acontecer, o professor e os alunos precisam estudar em conjunto. Para uma aula dinâmica, agradável e com êxito os alunos exercem um papel fundamental. No cotidiano escolar, se percebe que há distrações, seja pelo uso do celular, conversas diferentes do assunto estudado entre colegas, músicas no momento da aula, brincadeiras, entre outras coisas que impedem o professor de seguir sem interrupções seu planejamento. Com isso, o professor enquanto mediador desse processo de troca de conhecimento tem um papel importante de resgate da atenção, de si mesmo, de sua prática e da sua disciplina. Desse modo, a participação dos alunos nas aulas é significativa, pois, é preciso uma relação entre o fazer do professor e o aprender do aluno, ambos devem estar envolvidos para o aprendizado acontecer. Conforme os autores Cardeal; Mariano; Lucatelli (2012, p. 02):

A maior parte dos alunos quase sempre não mostra interesse em aprender o que o professor ensina, há diversas outras coisas que chamam mais a atenção deles do que seu professor e o que ele está lecionando. Tudo parece mais interessante: um barulho no pátio, alguém que se levanta para ir até o lixo, uma música no celular ou o inicio de um desentendimento entre os colegas de sala.

O número de alunos em uma sala de aula, também é difícil para o professor trabalhar com turmas numerosas, é fundamental salientar que o número de alunos por sala de aula é diferente entre escolas, isso vai depender da rede de ensino, quando observamos a realidade da escola pública, temos um quadro parecido. Com isso, surgem algumas limitações como: identificar, compreender e reparar as dificuldades encontradas pelos alunos, contudo, a realização de atividades diversas requer acompanhamento dos grupos, uma vez que cada aluno é único. Alguns alunos têm mais dificuldades específicas e diversas por isso a escolha da atividade é importante para atender as necessidades de todos. "Salas muito cheias dificultam a ensino-aprendizagem, tendo em vista a dificuldade de se adequar uma melhor metodologia para abranger um maior de alunos, pois cada um aprende de maneira diferente". (ANDRADE; SOUSA; FALCONIERE, 2013, p. 06).

Todo este processo, por sua vez, é desafiador para o docente. Deste modo, para o professor trabalhar com diferentes linguagens em suas ações didáticas é 
preciso o envolvimento da escola-comunidade, diálogos entre professores e alunos, pois para a aula ser boa e construtiva o professor precisa de seus pares. Portanto, para obter melhores resultados no ensino e na construção de uma formação cidadã dos alunos é essencial o comprometimento de todos que acreditam que a educação transforma a vida dos jovens, além de oferecer oportunidades. Mesmo diante das barreiras, é possível que o professor enquanto mediador do conhecimento supere-as, desenvolvendo sua autonomia e o pensamento crítico.

\section{O CINEMA ENQUANTO LINGUAGEM NA PRÁTICA DE ENSINO DE GEOGRAFIA}

O ensino de Geografia permite articular o cenário real do cotidiano pedagógico escolar com a realidade de vida, que acontece para além dos muros da escola. Isso oportuniza criar espaço de diálogo e reflexão que possibilita uma aprendizagem social situada nas experiências e vivências dos sujeitos imersos na aprendizagem. É criar estratégias que tornam possível lançar bases para uma formação cidadã, mobilizadora de uma ação que desvirtue uma lógica depositária de conhecimentos aleatórios, atribuindo a estes um sentido para a vida, para a cotidianidade, para as práticas sociais, ou seja, para a cidadania. A coexistência de diversas maneiras de condução da disciplina é que garantem o sucesso dela. Contudo, é preciso que o professor busque outros meios que facilitem a aprendizagem dos educandos. O acesso ao saber se restringe em várias possibilidades de como ensinar na sala de aula, instigando na construção do conhecimento geográfico dos educandos.

De acordo como os Parâmetros Curriculares Nacionais Ensino Médio (BRASIL):

Não há o que justifique memorizar conhecimentos que estão sendo superados ou cujo acesso é facilitado pela moderna tecnologia. O que se deseja é que os estudantes desenvolvam competências básicas que lhes permitam desenvolver a capacidade de continuar aprendendo. (BRASIL, 2000, p. 14).

Ensinar a olhar, refletir, questionar sobre a realidade faz parte do papel do professor, todavia, há um elo entre professor-conteúdo-aluno, visando no processo de construção de formação humana e intelectual do aluno. É ler o mundo, compreender suas representações quer seja através de sons, palavras ou imagens. 
Sob essa perspectiva, as diferentes linguagens fazem parte da prática educativa e constituem formas de letramento, representação e recriação do mundo, sobretudo, estimulando o aprendizado da leitura (THIEL; THIEL, 2009).

Para Napolitano (2003, p.89):

A sala de aula já vem incorporando, e sofrendo a intervenção dos meios de comunicação de massa com a utilização de jornais, revistas, programas de televisão. Porém, é preciso ver que esses meios podem ser considerados como salas de aula, como espaços de transformação de consciência, de aquisição de conhecimentos; que eles dependem de uma pedagogia crítica e que o sucesso dessa pedagogia crítica depende de como vamos ver e ouvir os produtos da indústria cultural.

Entre as diversas formas de linguagem, destaca-se a linguagem do cinema como mediador no processo de ensino-aprendizagem a ser explorada nas aulas de Geografia. Merece atenção o filme (e sua linguagem característica), ao propiciar o trabalho com conteúdos geográficos, possibilita que o aluno reflita, questione e analise os elementos constituintes do filme, pois a linguagem precisa ter finalidade e objetivo a ser cumprido, que tenha um propósito. Para Martins e Batista (2013, p. 04) "O desafio do professor é mostrar ao aluno o filme buscando leituras ambiciosas que façam que os alunos interessem em serem mais que um expectador, mas agente cheio de criticidade propondo relações entre o conteúdo e a linguagem fílmica".

Utilizar a linguagem do cinema nas aulas de Geografia proporcionará ricas discussões entre professores e alunos, contudo, os alunos terão a oportunidade de destacar vários elementos presentes no filme, identificando conteúdos que estão relacionados com a discussão. Além disso, há a integração de imagens e movimentos, para isso, basta estar atento às informações relevantes que formam a obra fílmica.

Para Pontuschka; Paganelli; Cacete (2007, p. 279):

A linguagem do cinema é uma produção cultural que pode ser utilizada em sala de aula a fim de abrir cada vez: mais horizontes intelectuais para a análise do mundo, necessária à formação da criança e do jovem. Para tanto, os professores precisam conhecer minimamente essa linguagem, que é muito rica porque integra imagens em movimento: a expressão oral e corporal, a cor, e tudo temperado pelas trilhas musicais. A linguagem cinematográfica é, com efeito, a integração de múltiplas linguagens. 
É fundamental ressaltar, que para ensinar Geografia temos várias possibilidades, através do uso do cinema os alunos poderão resgatar, construir e reconstruir elementos essenciais na compreensão de um conteúdo. De acordo com os Parâmetros Curriculares Nacionais do Ensino Fundamental (BRASIL, 1998, p. 33):

Também as produções musicais, a fotografia e até mesmo o cinema são fontes que podem ser utilizadas por professores e alunos para obter informações, comparar, perguntar e inspirar-se para interpretar as paisagens e construir conhecimentos sobre o espaço geográfico.

Inserir a arte do cinema nas aulas é significante para a prática docente, diante disso uma possibilidade para o uso do cinema pode ser feito através da produção de documentários de curta, numa perspectiva geográfica de noções. Visando assim, colaborar com o aprendizado global dos discentes e ter um novo olhar sobre a realidade em que convive. A partir da produção de documentários de curta os discentes passam de espectador passivo a crítico, recriando, identificando e interpretando os conteúdos principais, podendo ser tanto individual como em grupo. Como afirma Thiel e Thiel (2009, p. 15):

Portanto, o espectador recebe as imagens de um texto fílmico, mas nessa recepção não é passiva: o espectador lê e constrói os sentidos com base em vários contextos e a eles reage por meio de funções psíquicas de intelecção, cognição, memória e desejo, ou por meio de transformações de atitudes individuais e coletivas.

A inserção do cinema nas aulas de Geografia contribui significativamente no processo educativo dos alunos, onde perceberão a aula mais dinâmica e começarão a participar questionando e realizando perguntas que contempla os conteúdos, ademais instigando a curiosidade e a aprendizagem. Neste ínterim, o cinema visto pelo viés educativo perpassa informações prontas e acabadas, ou seja, o seu uso adequado faz com que a aprendizagem aconteça, apontando que os saberes são dinâmicos. O papel do filme na sala de aula ganha sentido quando provoca um movimento de aprendizagem entre professores e alunos, levando-os a criticidade, reflexão e interpretação, conforme o contexto e enxergando as informações como primeiro passo para a construção do conhecimento inacabado. É pensar o espaço geográfico e suas relações com meio, o homem, a sociedade e a natureza, construindo assim, o conhecimento geográfico basilar. 
Para Barbosa (2008, p. 112) "O papel do filme na sala de aula é o de provocar uma situação de aprendizagem para alunos e professores. A imagem cinematográfica precisa estar a serviço da investigação e da crítica a respeito da sociedade em que vivemos".

Trazer o cinema para sala de aula é provocar formação de atitudes cidadãs nos alunos, que são também sujeitos inacabados, possibilitando o debate entorno de conteúdos atuais apresentadas por filmes e documentários, tendo os acontecimentos geográficos como campo de análise. Inserir o cinema na sala de aula é propiciar que os sujeitos enquanto agentes de sua própria formação se tornem um espectador ativo, quando entram e saem da escola, possam atuar na sociedade e sejam capazes de reconhecer as transformações de ordem econômica, social, natural e cultural nas relações espaço-tempo. As Orientações Curriculares para o Ensino Médio (BRASIL) destaca que:

Do mesmo modo, a TV e o cinema na escola têm essa dupla disposição: entrar e se chocar com as formas tradicionais do ensino, incorporando as imagens ao ensino predominantemente auditivo; mas entrar na escola para sair de outro modo: sair da escola para se chocar com as formas convencionais da assistência. Assim como os diversos aspectos da vida entram na escola na forma de disciplinas - Sociologia, História, Geografia, Física, Língua, etc. - e sofrem aí uma releitura científica, passando a constituir uma visão de mundo, uma perspectiva diante da vida, a formação do homem não pode ocorrer como se quer - crítica e cidadã - se não concorrer para uma perspectiva crítica e cidadã dos meios de comunicação. (BRASIL, 2006, p. 129).

A linguagem cinematográfica é complexa e mistura emoção, envolvimento, enredo, ação, música, luz, movimento, mistério, desafio, suspense, pois o cinema como forma de linguagem para o ensino de Geografia sintetizará em uma mesma obra de arte a estética, o lazer, a ideologia e os valores sociais. Filmes frequentemente têm sido utilizados em aulas de diversas disciplinas e com bons resultados (NAPOLITANO, 2003). De acordo com Pontuschka; Paganelli; Cacete (2007, p. 280) "Para nós, geógrafos e professores de Geografia, o filme tem importância porque pode servir de mediação para o desenvolvimento das noções de tempo e de espaço na abordagem dos problemas sociais, econômicos e políticos". 
Trabalhar com o cinema dentro da sala de aula é despertar nos alunos a curiosidade, possibilitando o senso crítico, estético e cultural, apresentá-lo como fonte de cultura e agente transmissor de conhecimento. Antes de tudo, o professor deve ter claramente o objetivo que pretenda atingir com a reprodução da linguagem cinematográfica. Oliveira (2011, p. 04) assinala que:

O Cinema pode ser utilizado como recurso didático, pois assistir um filme é uma oportunidade excelente para conhecer novas culturas, ter visões diferenciadas e ampliar os seus conhecimentos. O principal tópico a definir são os objetivos que se pretende atingir com a reprodução do material cinematográfico. Em nenhuma hipótese se pode pensar no uso do cinema para preencher simplesmente o espaço do professor.

Mediante o exposto, o cinema vem contribuir nas aulas de Geografia, pois apresenta uma linguagem apropriada pelos professores, trabalhará com os variados conteúdos da referida disciplina, cabendo-lhe deixar claro para os alunos o que se pretende trabalhar e atingir ao inserir o filme nas ações docentes. Segundo Barbosa (2008, p. 112):

Nessa perspectiva, é preciso inserir o(s) filme (s) no enunciado didático que se pretende trabalhar (temas, conceitos, periodizações e configurações espaciais) e constituir buscas de interpretações balizadas em procedimentos com referências múltiplas - o saber escolar adquirido e o saber do mundo vivido - para permitir um diálogo mais amplo com e entre os estudantes.

É importante ressaltar que o professor enquanto mediador entre a obra (cinematográfica) e os alunos tenha em vista o objetivo que se pretende atingir ao trabalhar sistematicamente com o cinema em sala de aula, ou seja, o professor ao escolher um filme para incluir nas suas atividades escolares, deve levar em conta qual o uso possível do filme escolhido, adequação à faixa etária, articulação com o currículo ou conteúdo discutido e qual a cultura visual cinematográfica dos alunos. Esse enfoque de análise ajuda a orientá-lo na escolha e abordagem dos filmes (NAPOLITANO, 2003). Deste modo, é ter o propósito que se pretende atingir com a reprodução cinematográfica.

Sendo assim, o filme como linguagem jamais deve ser utilizada simplesmente para o preenchimento dos horários das aulas de Geografia, e sim, a função do filme 
para o ensino de Geografia é provocar uma situação de aprendizagem para alunos e professores que facilite o processo. Nessa perspectiva, propõe-se justamente que os educandos tenham um novo olhar sobre o cinema, interagindo com outras linguagens fazendo uma reflexão e sua relação com os elementos apresentados no filme (NAPOLITANO, 2003).

Em vista disso, o professor necessita de alguns procedimentos didáticos para desenvolver, tais como o planejamento e preparação do professor, apresentação e exibição, debate do filme e conclusão ou síntese do filme.

Dessa forma, exibir o filme ou vídeo sem discuti-lo, sem integrá-lo com o conteúdo da aula é insatisfatório, é preciso um "bom" filme ou vídeo, para introduzir uma nova discussão, para despertar a curiosidade, a motivação para novos conhecimentos. Trabalhar com o cinema para o ensino de Geografia o professor deverá usar temas que tratam das representações da vida nas grandes cidades, dos problemas ambientais, do convívio entre as etnias no mesmo país, entre outros para que os alunos questionem e desenvolvam um pensamento intelectual sobre o filme exibido na aula (NAPOLITANO, 2003).

Para tanto, após a exibição do filme em sala de aula, os educandos enquanto espectadores ativos realizem uma análise sobre o filme. Para isso, o educador orientará os alunos para que façam algumas anotações na medida em que assistem ao filme. De acordo com Thiel e Thiel (2009, p. 21) "Em uma sala de aula, ao realizar a análise do filme, é importante orientar os alunos para que façam algumas anotações á medida que assistem ao filme, mas, para isso, é preciso ter um objetivo em mente, já que são muitos os detalhes que podem ser observados".

O cinema como veículo e instrumento de ensinar, possibilita resgatar aspectos históricos, culturais e literários, uma vez que são trabalhadas temáticas presentes no cotidiano dos alunos, abrindo espaço para a discussão e o questionamento. Com isto, está se formando indivíduos com habilidades essenciais para o desenvolvimento de uma cidadania ativa em tempos de globalização em massa. 


\section{CONSIDERAÇÕES FINAIS}

No decorrer deste trabalho, foi possível perceber que o docente enquanto mediador da aprendizagem pode trabalhar na sala de aula com diferentes linguagens, visando desenvolver nos alunos o pensamento reflexivo, interpretação crítica e questionadora do saber. É essencial inserir as diversas linguagens com a finalidade e objetivo para alcançar o principal elemento, o aprender para a construção da cidadania plena dos discentes em situação de aprendizagem.

Vejamos que é uma tarefa desafiadora para o professor superar as interfaces encontradas na escola e em sala para tornar a aula 'boa' e significativa. As diferentes linguagens contribuem para a prática docente, proporcionando o entendimento de uma aula mais dinâmica, interativa e problematizadora, através de seu uso, vários conteúdos podem ser trabalhados nas aulas de Geografia.

Ser professor de Geografia nos dias atuais ultrapassa os muros da escola, é criar possibilidades para a construção de trabalhos críticos, que busquem a reflexão sobre as problemáticas das realidades sociais e cotidianas dos alunos para a formação cidadã e indivíduos ativos e atuantes para com a sociedade.

Inserir as linguagens: cinematográfica, musical e literária nas aulas, é satisfatório, despertando e instigando a curiosidade de cada aluno. Desta forma, assistir filmes é uma prática social tão importante do ponto de vista da formação cultural e educacional das pessoas, quanto a leitura de obras literárias, filosóficas, sociológicas e tantas mais. Dentro do contexto da utilização do cinema e da música como veículos e ferramentas de ensinar, temos a oportunidade de enfocar aspectos históricos e literários que convergem para a realidade.

É importante ressaltar que, a inserção das diferentes linguagens nas aulas de Geografia é significante, pois é uma maneira na qual os educandos refletem e promovem espaços de discussão e da avaliação de seu conhecimento, pois isto se faz necessário, na busca constante em adquirir habilidades cognitivas que façam sentido durante toda a vida dos alunos. 


\section{REFERÊNCIAS}

ANDRADE, F. G; SOUSA, L. V; FALCONIERE, A. G. Principais dificuldades enfrentadas pelos professores de química do CEIPEV. e contribuição do PIBID para superá-las. In: $5^{\circ}$ Congresso Norte e Nordeste de Química $3^{\circ}$ Encontro Norte-Nordeste de Ensino de Química (ANNQ), 2013, Natal. Anais ANNQ. Natal: UFRN, 2013. Disponível em:< http://annq.org/eventos/upload/1330465494.pdf >. Acesso em: 15 nov. 2016.

BARBOSA, J. L. Geografia e cinema: em busca de aproximações e do inesperado. In: CARLOS, A. F.A. A geografia na sala de aula. ed. 3. São Paulo: Contexto. 2008. p.109-133.

BEREZE， J; COSTA, C; ANDRADE, A. R. Recursos didáticos: o docente superando o tradicional nas aulas de geografia física. Caderno de Geografia, Minas Gerais, v. 25, n.43, p.78-89, jan.-jun. 2015.

BRASIL. MEC. Secretaria de Educação. Orientações curriculares para o ensino médio volume 3, Ciências humanas e suas tecnologias, 2006.

MEC. Secretária de Educação. PARÂMETROS CURRICULARES NACIONAIS (ENSINO FUNDAMENTAL) Terceiro e Quarto Ciclos, 1998.

MEC. Secretária de Educação. PARÂMETROS CURRICULARES NACIONAIS (ENSINO MÉDIO) Parte II- Linguagens, Códigos e suas Tecnologias, 2000.

MEC. Secretária de Educação. PARÂMETROS CURRICULARES NACIONAIS (ENSINO MÉDIO) Parte IV- Ciências Humanas e suas Tecnologias, 2000.

BULGRAEN, V. C. O papel do professor e sua mediação nos processos de elaboração do conhecimento. Revista Conteúdo, Capivari, v.1, n.4, p. 30-38, ago.- dez. 2010.

CALORI, J; PEREIRA, P. S. Geografia e a utilização dos recursos didáticos. 2011. p. 1-29. Trabalho de Conclusão de Curso (Geografia) - Universidade Federal de Alfenas, MG.

CARDEAL, D. M; MARIANO, M. L. S; LUCATELLI, N. G. O Trabalho Docente: Desafios e Dificuldades. In: II Seminário de Socialização do PIBID, 2012, Minas Gerais. Anais do II Seminário de Socialização do PIBID/UNIFAL-MG. Minas Gerais: UNIFAL, 2012. Disponível em <http://www.unifal-mg.edu.br/sspibid/sites/default/files/file/S02771.pdf>. Acesso em: 22 out. 2016.

CAVALCANTI, L. S. Geografia, escola e construção de conhecimentos. Campinas, SP: Papirus, 1998.

CECÍLIA, C; ALVES, E. Ensino de Geografia e suas diferentes linguagens no processo de ensino e aprendizagem: perspectivas para a educação básica e geográfica. Revista Geosaberes, Fortaleza, v. 6, número especial 3, p.27-34, fev. 2016. 
DEZOTTI, M. S; ORTIZ, A. C. M. O ensino de Geografia em escolas de educação básica na cidade de Santa Maria, RS: uma análise metodológica. Revista Disciplinarum Scientia, Santa Maria/RS, v.11, n. 1, p. 79-91, 2010.

JAQUES, M; KUEHN, T. G. A linguagem musical no ensino da literatura e na interpretação de textos líricos. Revista Maiêutica, n. 1, p.65-71, jan. 2013.

MARTINS, B. M. L; BATISTA, M. R. O ensino de Geografia e a linguagem de cinema. In: V Encontro Interdisciplinar de Educação (ENIEDUC), 2013, Paraná. Anais eletrônicos ANAIS DO V ENIEDUC - Encontro Interdisciplinar de Educação. Paraná/PR: UNESPAR/FECILCAM, $2013 . \quad$ Disponível em<http://www.fecilcam.br/anais/v_enieduc/data/uploads/geo/trabscompletos/geo06209 881939.pdf>. Acesso em: 12 ago. 2016.

MINAYO, S. C. M. (Org) Pesquisa Social: teoria, método e criatividade. Petrópolis-RJ: Vozes, 2002.

NAPOLITANO, M. Como usar o cinema em sala de aula. São Paulo: Contexto, 2003.

OLIVEIRA, D. R. O uso do cinema nas aulas de geografia: proposta de estudo da região Nordeste. 2011. p. 01-19. Artigo apresentado ao Curso de Licenciatura em GeografiaInstituto de Estudos e Pesquisas do Vale do Acaraú-IVA. Jijoca de Jericoacoara - CE.

OLIVEIRA Jr., W. M; GIRARDI, G. Diferentes linguagens no ensino de geografia. In: XI Encontro Nacional de Prática de Ensino de Geografia (ENPEG), 2011, Goiânia-GO. ANAIS XI ENPEG. Goiânia: UFRGS, 2011. Disponível em <https://poesionline.files.wordpress.com/2015/02/oliveirajrgirardi-20111.pdf>. Acesso em: 24 nov. 2016.

PONTUSCHKA, N. N; PAGANELLI, T. I; CACETE, N. H. Para ensinar e aprender Geografia. $1^{\text {a }}$ ed. São Paulo: Cortez, 2007.

SANTANA, L. M; BARBOSA, J. R. O uso da leitura da imagem nas aulas de Geografia e para o estudo da paisagem no ensino da geografia: reflexões a partir da experiência vivenciada elações na teoria práticas. In: V Encontro de Iniciação á Docência da UEPB (ENID), 2015, Campina Grande/PB. Anais V ENID / UEPB. Campina Grande/PB: UEPB, 2015. Disponível em

<http://www.editorarealize.com.br/revistas/eniduepb/trabalhos/TRABALHO_EV043_MD1_S A5_ID1258_30062015143948.pdf>. Acesso em: 22 out. 2016.

SANTOS, R. C. E; CHIAPETTI, R. J. N. Uma investigação sobre o uso das diversas linguagens no ensino de Geografia: uma interface teoria e prática. Revista Geografia Ensino \& Pesquisa, Santa Maria/RS, v. 15, n.3, p. 167-183, set./dez. 2011.

SILVA, M. J. A importância da música nas aulas de Geografia. 2014. p. 01-58. Trabalho de Conclusão de Curso (Geografia)- Universidade Federal de Campina Grande, Cajazeiras, PB. 
TEXEIRA, F. F; TUBINO, V. M. C.; SUZUKI, J. C. Geografia e literatura: uma alternativa para o ensino da questão indígena nas salas de aula. In: $V$ Encontro de Grupo de Pesquisa: “Agricultura, Desenvolvimento e Transformações socioespaciais (ENGRUPVI), 2011, Presidente Prudente/SP. Anais eletrônicos V ENGRUP. Presidente Prudente/SP. Disponível em <http://w3.ufsm.br/gpet/engrup/vengrup/anais/4/Fabiano\%20Teixeira-USP.pdf>. Acesso em: 15 out. 2016.

THIEL, G. C; THIEL, J. C. Movies takes: a magia do cinema na sala de aula. Curitiba: Aymará, 2009.

ZATTA, C. I; AGUIAR, W. G. O uso de imagens como recurso metodológico para estudar Geografia. Disponível em: <http://www.diaadiaeducacao.pr.gov.br/portals/pde/arquivos/2375-8.pdf> Acesso em: 12 out. 2016., 76p. 